\title{
An Unusual Case of Pre-Auricular Myiasis
}

\author{
Abhinaya shivakumar* and Dinesh Kumar Sathanantham \\ Department of General surgery, SDUMC, Kolar, India \\ Received: 制 May 26, 2018; Published: 制 June 05, 2018 \\ *Corresponding author: Abhinaya Shivakumar, Department of General surgery, SDUMC, Kolar, India
}

\begin{abstract}
Background: Myiasis-the feeding of fly larvae on living mammals has various clinical presentations depending on involved tissues or organs. The most recognised causative organism Dermatobia hominis. It involves various sites, rarity in this case report is the site of involvement and in turn occurrence of an underlying malignancy.

Case report: 68 year old lady, presented with an ulcer over the right side of the pre-auricular region for 1 year. On examination, it was infested with maggots larvae, which later on had a underlying squamous cell carcinoma with basal cell carcinoma. Patient underwent treatment for the same. Details of the case and the management is been presented.

Conclusion: Myiasis transmitted by Human Botfly, infests all cavities mainly ENT sites, in debilitated individuals. But its occurrence in a open space of the body, and its association is a rarity and has been reported in this case. Author concludes, that all myiasis should be managed meticulously.
\end{abstract}

Keywords: Myiasis; Pre-auricular; Pit; Squamous Cell Carcinoma

\section{Introduction}

Myiasis the feeding of fly larvae on living mammals has various clinical presentations depending on involved tissues or organs [1]. Myiasis is a common travel associated skin disorder as a consequence of short visits to developing countries [2,3]. The commonest clinical manifestations of myiasis infestation include inflammatory and allergic reactions. Ear, eye and respiratory tract infestations are also frequently encountered [2-4], and the human botfly. The most recognised causative organism Dermatobia hominis [5]. In Tropical countries like India, patient debilitation is the main causative etiology for the infection. We present an unusual case of pre-auricular myaisis of a debilitated lady who had no inciting lesion to result in a nidus to cause infection by myiasis larvae.

\section{Case Report}

68 year old lady, presented to the ER with complaints of fatiguability, prostration for a period of 1 month and a wound over the left side of the face for 1 year, wound appeared spontaneously, it progressed to an ulcer and was increasing to the current size. There was no h/o trauma, fever. No significant family, past history or travel history. On examination, patient was conscious oriented, vitals were stable. Local examination revealed on the right temporal and cheek region, an ulcer of $7 \times 3 \mathrm{~cm}$ over the preauricular region, solitary, margin was spreading which was inflamed and edematous with beaded edges, sero-sanguinous discharge, with active maggotfly infestation surrounding area is inflamed. On palpation, the ulcer was nontender, indurated edges, ulcer was resting on the zygomatico-temporal bone and depth been around $1 \mathrm{~cm}$, maggots larvae was present, ulcer was bleeding on touch (Figures 1 \& 2).

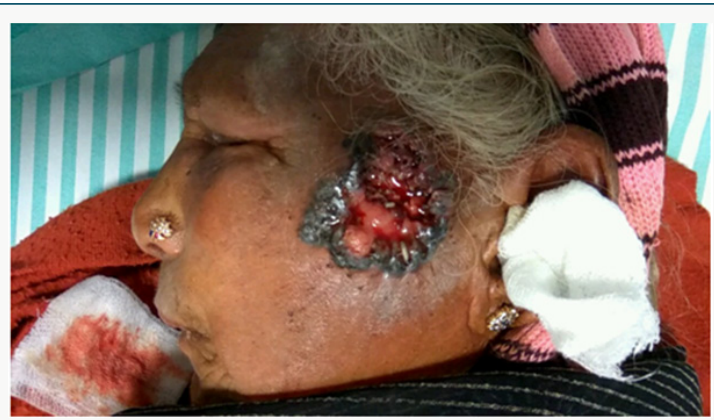

Figure 1: lateral view showing the ulcer with maggot infestation and beaded edges, closely observe the surrounding skin is edematous and inflamed. 


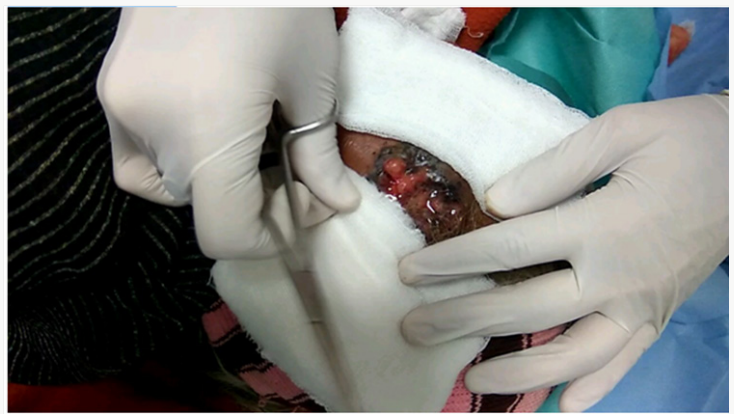

Figure 2: Procedure of removing the maggots.

After the removal of all the maggots (Figures 3 \& 4) with the help of ether, edge wedge biopsy was taken to rule out malignancy and local sterile dressing was done. Patient was started on antibiotics and subjected to CT Paranasal sinus, to rule out infiltration. Biopsy report revealed to be Squamous cell carcinoma with components of Basal cell carcinoma and CT showed no infiltration in the underlying structures. Patient underwent wide local excision and frozen section revealed clear margins. Post-operative recovery was good. Patient was discharged on POD\#7 and followed up regularly, 6 month follow-up revealed no signs of recurrence.

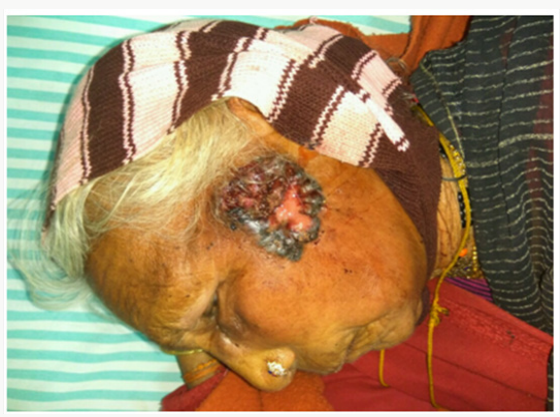

Figure 3: lateral view of the patient showing the ulcer Post procedural.

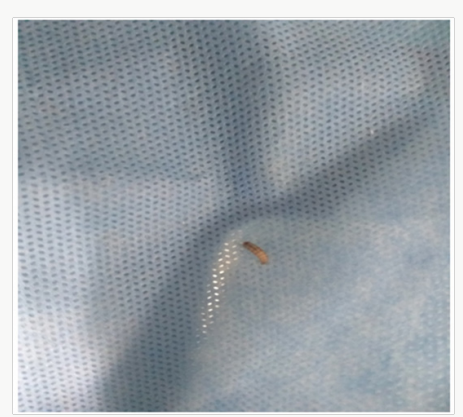

Figure 4: Maggot larvae removed from the ulcer site.

\section{Discussion}

Myiasis is defined as the invasion of mammalian tissues, organs, and cavities by the larvae of dipterous insects (two winged flies) [1]. Cutaneous myiasis is divided further into four clinically recognized manifestations, including open wound myiasis with soft-bodied maggots, subcutaneous tunnels or "creeping eruption," subcutaneous myiasis with migratory swellings, and furuncular myiasis. Myiasis may be obligatory where the host is essential for completion of the botfly cycle, or facultative, where the larval form of the botfly persists after transfer from a more conventional habitat [2,3]. D. hominis is the most common cause of furuncular myiasis in Central and South America. This disease should be considered for any patient who presents with a classical cutaneous lesion and a history of recent travel to the endemic regions of the Western hemisphere, especially those areas between central Mexico and Argentina [1,4,5]. D. hominis, which is found only in Central and South America, is also known as the human botfly, the tropical botfly, the warble fly, the macaw worm, and torsa10. It belongs to the family Oestridae and is found most commonly in hot and humid forests $[2,3,6]$. Although this fly has a rather unique life cycle and can come into contact with humans during 157 several of its stages, it is the larval form that commonly parasitizes both birds and mammals [5,7]. Mammalian hosts include not only humans, but also many wild and domestic animals. The patient in this case report stated that many of the dogs seen at his work sites and in the local villages demonstrated an abundance of subcutaneous nodules and localized swellings. Cutaneous myiasis typically presents with a characteristic clinical picture. Prominent diagnostic features include the following [8]:

a) History of recent travel in Central or South America.

b) One or more persistent, dome-shaped furuncles (typically located on exposed skin surfaces) which contain a central sinus or pore that drains serosanguinous or seropurulent fluid;

c) Localized symptoms including pruritis, fleeting sharp pains, and uncomfortable movement sensations within the lesion;

d) A small, white, retractile structure that appears in the aperture of the furuncle after irritation or occlusion;

e) A lack of generalized symptoms, signs, or abnormal laboratory findings.

f) The most common method to deal with suspected cutaneous myiasis is to occlude the central punctum thereby asphyxiating the larvae [9].

Spontaneous expulsion of the larvae has also been reported to occur with a number of traditional methods including the application of bacon fat, wax, glue, chewing gum, and nail polish to the affected tissue [7]. Once a larvae has been asphyxiated by occlusion of the punctum if not spontaneously expelled, it must be surgically removed. Patients in endemic areas resort to traditional methods as it is cheap and readily carried out by a lay man. In our case significant manual pressure was required for extrusion of the myiasis larvae [10].

\section{Acknowledgement}

Authors would like to thank Dr Manan shah, resident of the department of Pathology, Sri Devaraj Urs Medical College. 


\section{References}

1. Boggild AK, Keystone JS, Kain KC (2002) Furuncular myiasis: a simple and rapid method for extraction of intact Dermatobia hominis larvae. Clin Infect Dis 35(3): 336-338.

2. Boruk M, Rosenfrld RM, Alexis R (2006) Human botfly infestation presenting as a pre-auricular mass. Int J Pediatr Otorhinolarryngol $70(2): 335-338$.

3. Hall M, Wall R (1995) Myiasis of humans and domestic animals. Adv Parasitol 35: 257-334.

4. Steffen R, Rickenbach M, Wilhelm U, Helminger A, Schar M (1987) Health problems after travel to developing countries. J Infect Dis 156(1) 84-91.
5. Kenney RL, Baker FJ (1984) Botfly (Dermatobia hominis) myiasis. Int J Dermatol 23: 676-677.

6. Lowry MA, McEvoy PL (1992) Dermatobia hominis infestation: A case report. Mil Med 157(1): 683-684

7. Nunzi E, Rongioletti F, Rebora (1984) A Dermatobia hominis infestation. Postgrad Med J 60: 162-163.

8. Pallai L, Hodge J, Fishman SJ, Millikan LE, Phelps RG (1992) Case report: Myiasis-the botfly boil. Am J Med Sci 303(4): 245-248.

9. Elgart ML (1990) Flies and myiasis. Dermatol Clin J 8(2): 237-244.

10. Iannini PB, Brandt D, LaForce FM (1975) Furuncular myiasis. lAMA 233: 1375-1376.

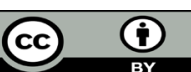

This work is licensed under Creative Commons Attribution 4.0 License

To Submit Your Article Click Here:

Submit Article

DOI: 10.32474/SCSOAJ.2018.01.000109

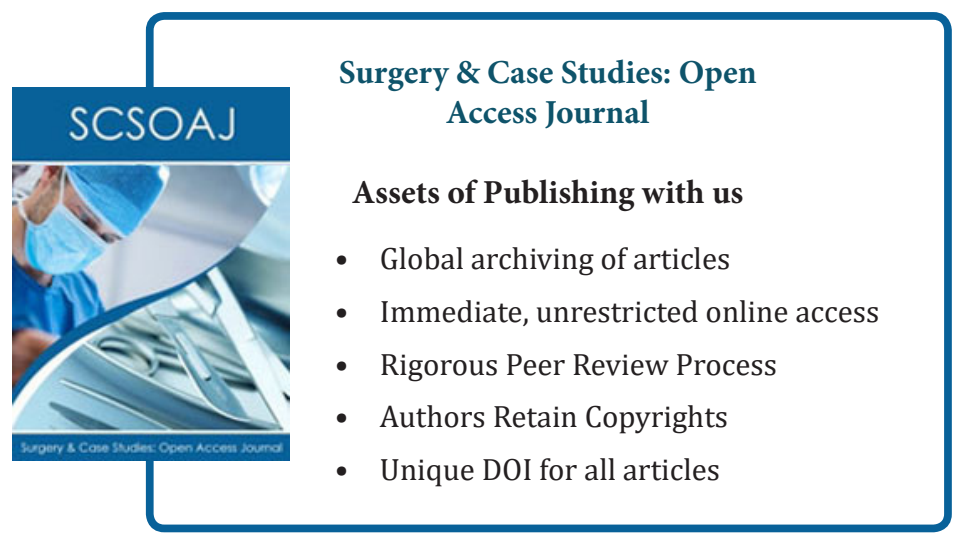

